\title{
Author's reply: Vaccinating healthcare workers: ethics and strategic behaviour
}

C Betsch (cornelia.betsch@uni-erfurt.de) ${ }^{1}$

1. University of Erfurt, Erfurt, Germany

Citation style for this article:

Betsch C. Author's reply: Vaccinating healthcare workers: ethics and strategic behaviour. Euro Surveill. 2015;20(2):pii=21007. Available online: http://www.

eurosurveillance.org/ViewArticle.aspx?Articleld=21007

Article submitted on 12 January 2015 / published on 15 January 2015

\section{To the editor:}

In the debate about vaccinating healthcare workers (HCWs) against influenza, the ethical argument stresses HCWs' social responsibility to be vaccinated against influenza to protect their patients. In his letter to the editor, Heath Kelly [1] highlights that this argument may be over-used, given that Cochrane reviews show that there is insufficient evidence that influenza vaccination in HCWs protects patients in hospitals from laboratory-confirmed influenza [2]. Besides this, it is argued that the ethical argument only holds for HCWs who are in contact with patients.

Analysing the vaccination decision that HCWs face as a social dilemma situation, as suggested in my original article [3], does not necessarily deliver the justification to put ethical pressure on HCWs. In short, due to indirect effects, vaccinations create positive externalities for other members of a society, because they reduce transmission. As vaccination itself can be costly in terms of time, effort, and potential side-effects, a rational strategy at the individual level may be to 'freeride', i.e. omit vaccination and thus avoid the costs associated with vaccination while enjoying the benefits of herd immunity. This choice may, however, compromise the collective benefit, because herd immunity cannot be reached when too much free-riding takes place $[3,4]$. Thus, this analysis suggests that if there is an indirect effect of vaccination, this aspect will influence the individual decision. There is an increasing amount of evidence, that this is actually the case, i.e. that individuals are more inclined to get vaccinated if this benefits others - providing that their own costs are low, e.g. $[3,5]$.

One crucial point in the analysis is the size of the indirect effect. The externalities of the individual decision vary according to the effectiveness of the vaccine. For influenza, theoretical vaccination coverage of $80 \%$ is required to establish herd immunity in the general population [6]. This may not be sufficient in hospital settings, where coverage may have to be higher instead. In fact, there is research suggesting that if $100 \%$ of HCW in nursing homes are vaccinated against influenza, the infections are reduced by $60 \%$ [7]. Thus, it is possible that for hospital situations vaccine coverage of HCWs higher than $80 \%$ or even up to $100 \%$ would be needed to attain positive effects.

One can consider two possible scenarios: If $100 \%$ coverage is necessary for herd immunity, free-riding is theoretically not possible. Nobody can opt-out without putting patients at risk. In such situations, ethical pressure seems necessary to ensure that full coverage is reached so as to provide the maximum possible protection of patients. To interrupt transmission chains, even HCW without direct contact to patients need to be immunised, assuming that such HCWs have contact with HCWs who directly work with patients. If a lower coverage of e.g. $80 \%$ is sufficient, however, $20 \%$ can free-ride without imposing a threat to herd immunity. In this situation social motives are likely to play a role: those who are either pro-socially oriented or whose social motives are activated should be more likely to get vaccinated [8]. Appeals to pro-sociality may also be effective here to reach an $80 \%$ uptake [9]. In order to examine if these different situations will impact behaviour and if pressure vs appeals will be suitable to reach the thresholds, controlled behavioural experiments should examine if awareness of the herd immunity threshold has an impact on HCWs' influenza vaccine uptake.

Differential treatment of HCWs with and without direct patient contact may pose additional problems. In economics, it is a well-known finding that free-riders in public goods dilemmas can nearly completely destroy cooperation [10] - it seems, that not only diseases are contagious, but that free-riding is contagious, too. Thus, those who do not contribute to the public good seem to undermine the trust in others' cooperation. From this point of view, it seems also advisable that there should be universal recommendations for HCWs rather than only for those who are in contact with patients - if evidence suggests that vaccinating HCWs is beneficial [11]. 
None declared.

Authors' contributions

$\mathrm{CB}$ wrote the letter.

\section{References}

1. Kelly H. Letter to the editor: Vaccinating healthcare workers: evidence and ethics. Euro Surveill. 2015;20(2):pii=21006

2. Ahmed F, Lindley MC, Allred N, Weinbaum CM, Grohskopf L. Effect of influenza vaccination of healthcare personnel on morbidity and mortality among patients: systematic review and grading of evidence. Clin Infect Dis. 2014;58(1):50-7. http:// dx.doi.org/10.1093/cid/cit580 PMID:24046301

3. Betsch C. Overcoming healthcare workers vaccine refusal - competition between egoism and altruism. Euro Surveill. 2014;19(48):20979. http://dx.doi.org/10.2807/1560-7917. ES2014.19.48.20979 PMID:25496574

4. Fine P, Eames K, Heymann DL. "Herd immunity": a rough guide. Clin Infect Dis. 2011;52(7):911-6. http://dx.doi.org/10.1093/cid/ ciroo7 PMID:21427399

5. Galvani AP, Reluga TC, Chapman GB. Long-standing influenza vaccination policy is in accord with individual self-interest but not with the utilitarian optimum. Proc Natl Acad Sci USA. 2007;104(13):5692-7. http://dx.doi.org/10.1073/ pnas.0606774104 PMID:17369367

6. Plans-Rubió $P$. The vaccination coverage required to establish herd immunity against influenza viruses. Prev Med. 2012;55(1):72-7. http://dx.doi.org/10.1016/j.ypmed.2012.02.015 PMID:22414740

7. van den Dool C, Bonten MJM, Hak E, Heijne ICM, Wallinga I. The effects of influenza vaccination of health care workers in nursing homes: insights from a mathematical model. PLoS Med. 2008;5(10):e200. http://dx.doi.org/10.1371/journal. pmed.0050200 PMID:18959470

8. Balliet D, Parks C, Joireman J. Social value orientation and cooperation in social dilemmas: a meta-analysis. Group Process Intergroup Relat. 2009;12(4):533-47. http://dx.doi. org/10.1177/1368430209105040

9. Ajzen I, Fishbein M. Understanding attitudes and predicting social behaviour. Englewood Cliffs, NJ: Prentice-Hall; 1980.

10. Fehr E, Schmidt KM. The economics of fairness, reciprocity and altruism - Experimental evidence and new theories. In SC Kolm \& JM Ythier (Eds.), Handbook on the Economics of Giving, Reciprocity and Altruism. Amsterdam: North-Holland Publishing;2006. pp. 615-91.

11. English PB. Healthcare workers and flu vaccination: egoism, altruism, and trust. Weblog. [Accessed 13 Jan 2015]. Available from: http://peterenglish.blogspot.co.uk/2014/12/healthcareworkers-and-flu-vaccination.html 